\title{
The Development of Rumen Microbial Populations in Lambs and Calves Under Various Conditions of Management
}

\author{
By J. MARGARET EADIE \\ The Rorvett Research Institute, Bucksburn, Aberdeen, Scotland
}

(Received 23 November 1961)

\begin{abstract}
SUMMARY
The development of the rumen flora and fauna has been followed by microscopic observations of rumen fluid from 58 young lambs and calves kept under different conditions of management; including remaining with the dam, early weaning and artificial inoculation into the rumen. Ciliatefree animals were successfully maintained by isolation from direct contact with other ruminants from an early age, but it was noted that greater space should be left between cattle than between sheep. The general effect of different diets and treatments proved similar in calves and lambs but certain differences were noted in their flora. Certain large bacteria developed in isolated lambs without direct contact between animals. Some generalizations, particularly the effect of a high concentrate diet, were applicable to all animals examined, but there were variations between individual animals. In the establishment of rumen ciliates diet was the governing factor and artificial inoculation with ciliates proved as effective as constant contact with the dam. Although the ciliate-free animals showed no differences in performance certain differences in the rumen flora common to isolated calves and lambs were noted.
\end{abstract}

\section{INTRODUCTION}

The normal adult ruminant harbours an active mixed microbial population of bacteria and protozoa which play a significant role in the breakdown of the components of the ration. There is a range of morphologically different species of bacteria (see, for instance, Moir \& Masson, 1952; Smiles \& Dobson, 1956), and the principal protozoa are ciliates, although some small flagellates are also present. The rumen ciliates are of two families: the highly complex Ophryoscolecidae of which there are many species and the holotrich species Isotricha prosoma, $I$. intestinalis and Dasytricha ruminantium which belong to the Trichostomatidae. It has been said that this mixed microbial population is not found in the very young milk-fed animal but is first observed when the rumen itself has enlarged and solid food has been consumed.

Considerable interest has been shown in the development of rumen microbial populations in calves kept on different rations and under varying conditions of management (Pounden \& Hibbs, 1948 $a, b, 1949$, 1950; Bryant, Small, Bouma \& Robinson, 1958; Bryant \& Small, 1960). The value of artificial inoculations of rumen contents in early weaning has been studied, as for example by Preston (1958), but the low rumen $\mathrm{pH}$ proved to be a limiting factor in the establishment of an adult type of microbial population. Pounden \& Hibbs $(1948 a, b)$ and Eadie,

Vol. 29, No. 3 was issued 27 November 1962 
Hobson \& Mann (1959) have noted the significance of the ration in regulating the $\mathrm{pH}$ and hence the microbial population in calves and Purser \& Moir (1959) have demonstrated the relationship between minimum rumen $\mathrm{pH}$ and ciliate numbers in mature sheep. Phillipson (1955) quotes the range of $\mathrm{pH}$ values within the rumen for animals on a normal ration as 5.9-7.4 for cattle and 5.3-7.3 for sheep, and Briggs, Hogan \& Reid (1957) who obtained $\mathrm{pH}$ values as low as 4.5 for sheep on certain rations considered that a rumen $\mathrm{pH}$ below 5.0 was not normal for an adult animal.

The microbial populations of different domestic ruminant species have generally been considered to be strictly comparable yet no detailed comparison has been made and no one has studied the rumen ciliate populations in vivo from the point of view of inter-relationships between the component species.

This paper records a study of the development of the rumen microbial population in a total of 58 young ruminants - calves and lambs-kept under various conditions of management including the natural one of remaining with the dam. The questions considered to be of special interest in this study were to what extent the microbial population was governed by age of host, diet, availability of micro-organisms and species of ruminant and in addition whether there were individual variations between animals. Particular note has been taken firstly of the development of organisms under different treatments and secondly of any striking inter-relationships between bacteria and ciliates. In a second paper (Eadie, 1962), observed inter-relationships between the different species of ciliates within these young ruminants are discussed. Finally, general comparisons have been made with calves and lambs kept completely free from ciliates by isolation.

Becker \& Hsiung in 1929 first demonstrated that the rumen ciliates are only passed from animal to animal by direct transfer between hosts, of saliva containing the active organisms. Resistant cysts have never been found and viable rumen ciliate forms are not present either in the food or faeces. The active organisms which reach the host's mouth during rumination are rapidly killed by drying or exposure to air. Thus transfer is normally effected by direct mouth-to-mouth contact between animals. This feature of the rumen ciliates has greatly facilitated the present study since it is possible to control the ciliate fauna by appropriate spatial separation of animals.

\section{METHODS}

\section{Young animals}

Animals

Table 1 lists the lambs and their management, Table 2 the early weaned calves and Table 3 the twin calves which were weaned at a later stage; one further calf, ' $Z$ ', was maintained free from ciliates on the late, weaning system. All animals received colostrum for at least 3 days and thereafter, where milk was fed, whole cows' milk was used. The lambs from any 1 year were born within a short time of each other and were therefore studied over much the same period of time.

\section{Adult rumen-cannulated sheep}

Throughout the period of the experiments a number of adult rumen-cannulated sheep were maintained to provide rumen fluid from which the inocula were prepared. Some of these were fed on hay and a cereal-based diet and the remainder 
on hay and grass cubes. Three partially-faunated sheep in which limited ciliate populations (see $(C),(D)$ and $(E)$ p. 566), had been established by the method of Eadie \& Oxford (1957), were maintained in isolation.

Table 1. Rations and management of lambs

\begin{tabular}{|c|c|c|c|c|c|}
\hline Breed & Lamb no. & Management* & $\begin{array}{l}\text { Age at time } \\
\text { of first } \\
\text { inoculation of } \\
\text { rumen ciliates } \\
\text { plus bacteria } \\
\text { (days) }\end{array}$ & $\begin{array}{c}\text { Age } \\
\text { regular } \\
\text { sampling } \\
\text { started } \\
\text { (days) }\end{array}$ & $\begin{array}{c}\text { Age } \\
\text { stomach tube } \\
\text { samples } \\
\text { terminated } \\
\text { (days) }\end{array}$ \\
\hline $\begin{array}{l}1956 \text { Blackface } \\
\text { Blackface }\end{array}$ & $\begin{array}{l}\mathbf{5 0} \\
\mathbf{5 1}\end{array}$ & $\begin{array}{l}\mathbf{D} \\
\mathbf{D}\end{array}$ & $\begin{array}{l}42 \\
42\end{array}$ & $\begin{array}{l}42 \\
42\end{array}$ & $\begin{array}{l}223 \\
223\end{array}$ \\
\hline 1958 Shetland $\times$ Cheviot & 305 & $\begin{array}{c}\text { B } \\
\text { Weaned } \\
135 \text { days }\end{array}$ & 147 & 27 & 167 \\
\hline Shetland $\times$ Cheviot & 327 & $\begin{array}{c}\text { B } \\
\text { Weaned } \\
145 \text { days }\end{array}$ & 177 & 22 & 295 \\
\hline 1959 Cheviot & $90 \mathrm{TI}$ & $\mathbf{A}$ & - & 7 & 91 \\
\hline Cheviot & $92 \mathrm{T2}$ & $\mathbf{A}$ & 一 & 6 & 90 \\
\hline Cheviot & 94 & $\mathbf{A}$ & - & 9 & 100 \\
\hline Cheviot & $91 \mathrm{~T} 1$ & C & 8 & 6 & 141 \\
\hline Cheviot & $93 \mathbf{T 2}$ & $\mathbf{C}$ & 7 & $\mathbf{5}$ & $133 \ddagger$ \\
\hline Cheviot & 95 & $\mathrm{CE}$ & - & 8 & $134 \%$ \\
\hline Cheviot & 96 & $\mathrm{CE}_{1}$ & 678 & 7 & $138+$ \\
\hline Cheviot & 88 & $\begin{array}{c}\text { B } \\
\text { Weaned } \\
118 \text { days } \\
\text { B }\end{array}$ & 113 & 7 & 133 \\
\hline & & $\begin{array}{l}\text { Weaned } \\
118 \text { days }\end{array}$ & & 8 & 174 \\
\hline Blackface & $411 \dagger$ & $\mathbf{B}$ & - & 7 & 88 \\
\hline Blackface & $418 \dagger$ & $\mathbf{B}$ & - & 7 & 88 \\
\hline 1960 Blackface & $\lceil 221$ & CE & - & 22 & $205 \ddagger$ \\
\hline Blackface & $222 \S$ & $\mathrm{CE}_{2}$ & 182 & 22 & 233 \\
\hline $\begin{array}{l}\text { Border Leicester } \times \\
\text { Cheviot }\end{array}$ & $\Gamma 230 \S$ & C & 18 & 18 & $185 t$ \\
\hline $\begin{array}{l}\text { Border Leicester } \times \\
\text { Cheviot }\end{array}$ & $231 \S$ & C & 18 & 18 & 211 \\
\hline $\begin{array}{l}\text { Border Leicester } \times \\
\text { Cheviot }\end{array}$ & $232 \S$ & $\mathbf{C}$ & 14 & 14 & $207 \div$ \\
\hline Blackface & $241 \mathrm{~TB}$ & $\mathbf{B}$ & - & 9 & 44 \\
\hline Blackface & 242 T 3 & B & - & $\boldsymbol{9}$ & 44 \\
\hline Blackface & {$[245 \mathrm{~T} 4$} & B & - & 10 & 42 \\
\hline Blackface & 246 T 4 & $\mathbf{B}$ & - & 10 & 42 \\
\hline Blackface & 247 & B & - & 9 & 44 \\
\hline
\end{tabular}

* A, with ewe, outdoors on grass; $\mathbf{B}$, with ewe, indoors with access to ewe's concentrates; $\mathrm{C}$, bottle-fed whole milk, grass $a d l i b$ at 21 days, weaned on to concentrated lamb ration $+a d l i b$ grass at 93 days; $D$, bottle-fed, weaned at 77 days on to hay ad lib + concentrate mixture; $\mathbf{E}$, completely isolated; $E_{1}$, completely isolated until 678 days; $E_{2}$, completely isolated until 182 days.

$\dagger$ Ewe on low calcium and phosphorus ration and milk yield was rather small.

$\ddagger$ Animal cannulated and kept on further experiments.

$\$$ Used for antagonism experiments (Eadie, 1962).

\} Creep fed together with concentrates, from 44 days.

T1, etc., Twins.

[ In the same pen together. 
The ciliate populations available for inocula were therefore as follows:

(A) Entodinium and holotrich species with Polyplastron multivesiculatum (Dogiel $\&$ Fedorowa) as the predominant large Ophryoscolecid with various other ciliates such as Diploplastron affine (Dogiel \& Fedorowa) and, in early experiments, Ophryoscolex tricoronatus (Dogiel).

(B) Entodinium and holotrich species with the large Ophryoscolecid genera Eudiplodinium and Epidinium either together or separately.

$\left(B_{1}\right)$ A population like $B$ but without holotrich organisms.

(C) Entodinium species alone (one isolated animal).

(D) Entodinium species, Dasytricha ruminantium and Epidinium spp. (one isolated animal).

(E) Entodinium species, Isotricha prostoma, I. intestinalis and Polyplastron multivesiculatum (one isolated animal).

Table 2. Calves-early weaning treatments

The numbers under the treatment headings are those by which the calves are mentioned in the text.

\begin{tabular}{|c|c|c|c|}
\hline $\begin{array}{c}(a) \\
\text { Grass available at } \\
7 \text { days. Concen- } \\
\text { trates }+0.8 \mathrm{~g} \cdot / \mathrm{lb} \text {. } \\
\text { aureomycin at } \\
15 \text { days. Weaned } \\
\text { at } 21 \text { days }\end{array}$ & $\begin{array}{c}(b) \\
\text { As }(a) \text { but without } \\
\text { aureomycin }\end{array}$ & $\begin{array}{c}(c) \\
\text { Concentrates } \\
\text { available at } 7 \text { days. } \\
\text { Weaned on to all } \\
\text { concentrates } \\
\text { at } 21 \text { days }\end{array}$ & $\begin{array}{c}(d) \\
\text { Grass at } 7 \text { days } \\
\text { Weaned on to } \\
\text { varied ratios of } \\
\text { grass: concentrates } \\
\text { at } 21 \text { days }\end{array}$ \\
\hline 2 & 86 & 610 & $4 * \dagger$ \\
\hline $3 * \dagger$ & - & 611 & 5 \\
\hline 6 & - & 612 & 7 \\
\hline 8 & - & 613 & 21 \\
\hline 71 & - & - & $\mathbf{3 5 \dagger}$ \\
\hline 78 & - & - & 72 \\
\hline $79 \ddagger$ & - & - & $84 \mathrm{~T} 1$ \\
\hline 80 & - & - & - \\
\hline $81 \ddagger$ & - & - & - \\
\hline $85 \mathrm{Tl}$ & - & - & - \\
\hline $\begin{array}{l}* \text { See Eadi } \\
\dagger \text { Used in a } \\
\$ \text { Fed milk } \\
T \text {, Twins. }\end{array}$ & $\begin{array}{l}\text { Mann \& Hobson (1 } \\
\text { agonism experime } \\
\text { y teat whereas all }\end{array}$ & $\begin{array}{l}\text { 959). } \\
\text { ats (Eadie, 1962). } \\
\text { the others fed milk }\end{array}$ & bucket. \\
\hline
\end{tabular}

Normal

\section{Housing}

The early-weaned calves and the mature cannulated sheep were kept in separate pens with wooden sparred partitions so that there was some contact between neighbouring animals of the same age. This also applied to the lambs 411, 418, 241, 242, 245, 246 and 247 which were kept in pens with the ewes. The other lambs kept indoors with the ewe were fairly well isolated from contact with other animals as were the lambs kept together in the same pen. The lambs and ewes out on grass were in the same field as Shetland ewes but were never seen to mingle very much.

\section{Isolation}

The development of a routine procedure by which animals could be successfully 


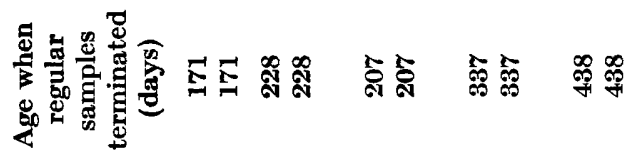

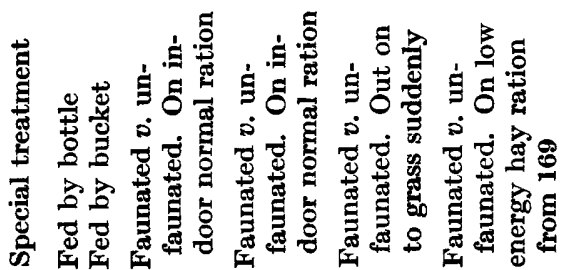



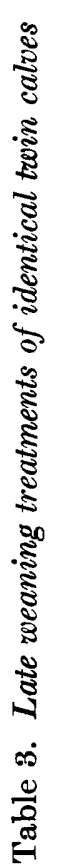

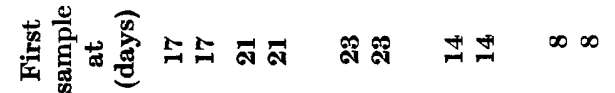

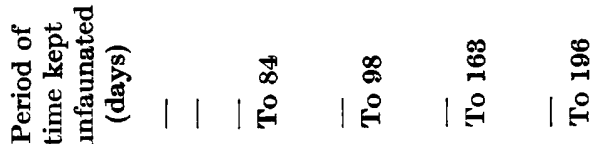

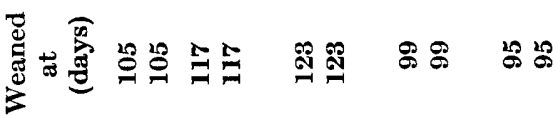

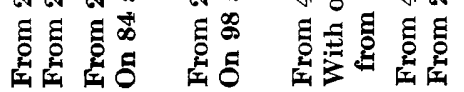

产

层

巡

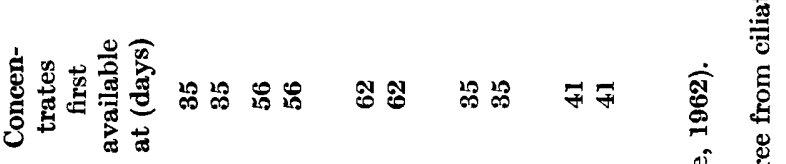

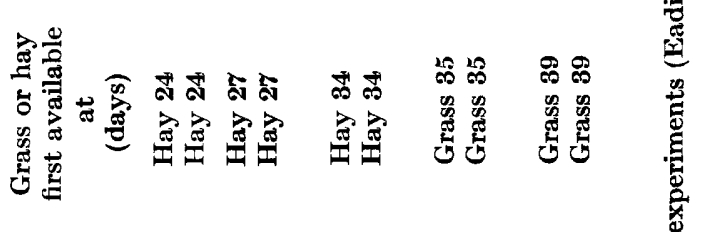


and indefinitely maintained completely free from rumen ciliate contamination was carried out over a long period of time and some modifications in management and design of housing proved necessary. The object was to prevent physical contact between animals at all times and to avoid chance transfer of live ciliates in saliva or rumen liquor during cleaning, feeding or sampling. At the same time in order to obtain otherwise healthy normal animals it was advisable to leave them within sight and sound of other animals and in addition for this work it was necessary not to eliminate the possibility of aerial transfer of rumen bacteria. Some authors (Bryant \& Small, 1960) have suggested that it is essential to use disinfectants on workers and apparatus together with changing of clothes before animals are handled. In the present work constant general care in the order of handling the animals, and rigorous washing of all contaminated material with soap and water, has proved adequate.

(a) Partially faunated isolated cannulated sheep. These sheep were kept in the same room as other mature sheep but the most satisfactory housing proved to be a wooden crate similar to a metabolism crate. This was placed within a solid partitioned pen (see $(b)$ below). The crates were sufficiently narrow so that the sheep could not turn and they were placed in line; nose to tail; so that each sheep was $5 \mathrm{ft}$. from the rear of the crate in front.

(b) Isolated lambs. From up to 3 days of age the ciliate-free lambs numbers $\mathbf{9 5}$, 96, 221 and 222 (Eadie \& Hobson, 1962) were kept isolated in pairs in pens with high wooden partitions made from closely fitting, interchangeable, smooth boards. These pens were specially designed for this work. Since animals tended to chew through even this smooth wood some of the more accessible boards were covered with thin steel sheeting. As with the partially faunated sheep mature animals were present in the same room.

After rumen cannulation and when sufficiently large, lambs 95 and 96 were transferred to crates identical with those used for the sheep mentioned in (a).

(c) Isolated calves. Each member of a pair of twins was housed and managed in the same way except that extra care was taken to prevent contamination of the ciliate-free animals. The calves $\boldsymbol{P}, \boldsymbol{Q}, \boldsymbol{X}$ and $\boldsymbol{Y}$ were tethered in solid partitioned cow stalls but these were unsatisfactory when the animals grew since contact became possible and the animals were too accessible to visitors, or to chance stray ruminants. The pens used for $N, O, F$ and $G$ were of the design used for the young isolated lambs but were necessarily larger. A sealed perspex window was fitted into one of the boards of the partitions to allow the animals to see their neighbours. The calves were tethered in a position of nose to tail.

\section{Sampling and inoculation}

Samples were initially obtained by polythene stomach tube from all the young animals although some were later fitted with rumen cannulae. When using a stomach tube on young lambs it is possible to obtain abomasal-not ruminal samples but such samples could be recognized by the low $\mathrm{pH}$ and the indistinct nature of the Gram smear. In order to limit aeration of the samples those of 5-25 ml. were collected in McCartney bottles, larger samples in flat medicine bottles and the screw caps were rapidly replaced. The samples were then immersed in water in a 
thermos flask at $37^{\circ}-39^{\circ}$ before being carried to the laboratory. Stomach tube samples were also taken from those ewes that were not fitted with rumen cannulae.

Samples from lambs were taken $4 \mathrm{hr}$. and from calves $4 \frac{1}{2} \mathrm{hr}$. after the morning feed, usually at weekly intervals. Inoculations were given immediately after the sample had been taken, it being assumed that ciliate organisms present after one week had become established and that any which had survived but not multiplied after the previous inoculation would have disappeared within the week.

Occasionally whole rumen liquor was used as inoculum but in general a concentrated mixed inoculum containing most of the ciliates and many of the bacteria from $500 \mathrm{ml}$. of rumen liquor was used for each calf and the organisms from $\mathbf{2 5 0} \mathrm{ml}$. for each lamb. Rumen liquor from the rumen cannulated sheep was used (see p. 564). The inoculum was obtained by sedimentation in a separating funnel to which $0.5 \%(w / v)$ galactose was added (Eadie \& Oxford, 1955) and the base layer from the funnel was used directly. Where closely comparable inocula were necessary every effort was made to use samples from animals on the same ration and with populations of ciliates similar in both types and numbers. In addition organisms from a concentrate-fed sheep were used to inoculate an animal on that type of ration.

\section{Examination of samples}

The $\mathrm{pH}$ of each sample was determined with a meter as soon as possible. $\mathbf{A ~ p H}$ below 6.0 was considered to be 'low' and above 6.5 to be 'high'. Gram smears and direct microscopic examinations of warmed wet mounts were made from all samples and a small volume of the rumen liquor was fixed with an equal volume of $10 \%(\mathrm{v} / \mathrm{v})$ formalin and stored in a sealed bottle.

For the variations of microbial population under consideration thorough microscopic examination of samples under uniform conditions was believed to give as accurate an assessment as attempts to count the organisms. Accordingly for each sample wet preparations were made with standard slides and coverslips. The same magnifications and the same volume of the well mixed samples were used throughout. These examinations could be repeated on the fixed material as and when samples from comparable animals became available.

\section{General observations}

The general performance and weekly weights of the isolated ciliate-free and control identical twin calves were recorded and the isolated ciliate-free lambs and their controls were also compared.

\section{RESULTS AND DISCUSSION}

Although relatively few of the animals from Tables 1,2 and 3 are actually cited in the results, generalizations are based on results of the examination of all animals. Thus where a particular treatment is not specifically mentioned it can be assumed that there was no observed effect.

\section{(a) Lambs}

\section{Time of first development of ciliate protozoa}

There was very little difference between the times of arrival of ciliates in lambs on the various treatments provided that the ration favoured a fairly high rumen $\mathrm{pH}$. 
Ciliates could be present as early as 9 days, were in most lambs by 14 days and were quite definite by 21 days, which is regarded as the stage at which rumination begins (Walker, 1959). There were only scattered fragments of solid food material in the rumen before that age. There was a tendency for an earlier appearance of the ciliates in the outdoor lambs but this was probably due to the favourable ration rather than the presence of the ewe. The establishment of ciliates in the indoor lambs with the ewe seemed to be largely governed by the percentage of concentrates in the ration which in turn affected the rumen $\mathrm{pH}$ (see Pounden \& Hibbs, 1948b, for similar observations on calves).

In general, if the $\mathrm{pH}$ was lower than $6 \cdot 0$ only small numbers of ciliates were likely

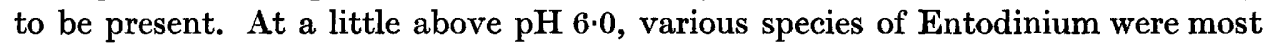
frequent and at a $\mathrm{pH}$ greater than $6 \cdot 5$, a mixed population including the larger Ophryoscolecids developed. In several lambs the large Ophryoscolecids became established before the holotrichs. This ciliate development was irrespective of the source of the ciliate inoculum and despite the fact that a lamb with the ewe was presumably constantly being inoculated by direct contact whereas the artificial inoculations were only at weekly intervals.

\section{(b) Calves}

The first development of a ciliate population in young calves followed a very similar pattern to that in lambs although there was a tendency for Isotricha species to be more rapidly established in calves. Ciliates that had been inoculated into early weaned calves at 8 days old were quite frequently established by the 15th day and this was often a mixed population. However, invariably a change from milk or roughage to a high concentrate ration, with the resultant drop in rumen $\mathrm{pH}$, led to the disappearance of ciliates. The calves 612 and 613 weaned on to a ration consisting entirely of concentrates did not develop ciliates while observations were carried on, which was up to 5 months of age. The use of milk feeding by teat encouraged the maintenance of a high $\mathrm{pH}$ in the young calf rumen, presumably by the reduction of overspill of milk into the rumen, and this stimulated early development of ciliates in calves 71,81 (Table 2) and A (Table 3). However, whatever the method of milk feeding, when concentrates were fed the rumen $\mathrm{pH}$ dropped and ciliates disappeared.

When calves were weaned on to diets with certain ratios of roughage to concentrates (Table $2(d)$ ) the rumen $\mathrm{pH}$ could be kept above 6.0 and the inoculum of ciliates given at 8 days could be maintained. However, care had to be taken that the ration was adequate to maintain the calves. Calves 5 and 7 developed a thriving mixed rumen ciliate population on a $2: 1$ and 3:1 roughage to concentrate ration respectively, but became very weak so that the ration had to be changed (Eadie, 1959). A mixture of equal quantities of roughage to concentrates has been found to maintain both calf and ciliates, especially Entodinium species and Isotricha species in the first few weeks.

\section{Establishment of ciliates after a period of low rumen $\mathrm{pH}$}

In both calves and lambs the first ciliates to develop after a prolonged period of low $\mathrm{pH}$ were Entodinium species. In calves Isotricha species became established very shortly after the entodinia and the large Ophryoscolecids were the last to develop. 
This contrasted with the tendency after the same type of inoculum, for a mixed population to develop at once in the young calf where the rumen $\mathrm{pH}$ had never dropped below 6.5. When the rumen $\mathrm{pH}$ of a calf in which a mixed ciliate population was already established dropped, then Entodinia and Isotricha species were the last to go.

In the majority of lambs which were examined after a period of low rumen $\mathrm{pH}$, the holotrich organisms tended to develop later than the Ophryoscolecids.

The loss of, or more frequently a great reduction in numbers of, ciliates, with a drop in rumen $\mathrm{pH}$ occurred in older animals in much the same way as in young ones.

\section{(a) Lambs}

\section{Establishment of ciliates after a period of isolation}

The isolation of the lambs 95, 96, 221 and 222 proved very satisfactory. As mentioned by Eadie \& Hobson (1962), very small numbers of small entodinia appeared in lamb 95 for 3 weeks but did not become established. They most probably were transferred in droplets from calf $G$ which was only a short distance away (see below). Otherwise, no ciliates were ever seen in the isolated lambs until they were inoculated.

Apart from the remarkable failure of these small entodinia to multiply in lamb 95, no difficulty has been encountered in establishing ciliates in lambs that have grown to a considerable age without them on a ration suited to their establishment. When a mixed inoculum was given to lamb 96 at 20 months, a thriving mixed population had developed after 6 days and in this case entodinia and holotrichs were the first to become established. Similarly, when lamb 222 was inoculated with a limited number of ciliate species taken from the isolated sheep in turn, it took only a short time for each species to develop. In this lamb holotrich species were slower to develop than the other species.

\section{(b) Calves}

At about 50 weeks of age small entodinia appeared in both calf $O$ and calf $G$ and this despite the strict precautions taken to prevent cross contamination. Although calf $G$ was kept for a further 11 weeks in the same pen no larger organisms developed. It seems possible that the small entodinia can be carried in droplets and that calf $G$ was contaminated by calf $F$ which was tethered in its pen only $8 \mathrm{ft}$. behind calf $G$. Similarly, a year previously when calf $O$ became contaminated, calves $N$ and $O$ were in the same neighbouring pens used by $F$ and $G$. It seems therefore, that in isolating calves to prevent rumen ciliate development the distance between animals should be greater than that used in this work and incidentally greater than that required between isolated sheep.

When calves $Y$ and $Q$ were inoculated, the proportion of concentrates in the ration was still fairly high and only entodinia and isotrichs developed.

After small entodinia had become established by contamination in calf $O$ at 23 weeks of age, it was turned out into a field along with its twin $N$ and other calves so that it became inoculated by direct contact. The rumen $\mathrm{pH}$ of calf $O$ at this time was 6.6-7.0. In two weeks a large mixed population of Type B Ophryoscolecids was present along with entodinia but it was 3 weeks later before Dasytricha and Isotricha species were present in fair numbers. This observation is completely com- 
parable with the order of development of ciliates under the same conditions, observed by Bryant et al. (1958). Similarly, in calf $G$ there was a time lag in the development of the holotrichs although there was a large proportion of these organisms in the inoculum.

It appears, therefore, that irrespective of the numbers in the inocula an early development of Isotricha in both very young and older ciliate-free calves is favoured by fairly acid rumen conditions (a $\mathrm{pH}$ of $6 \cdot 0-6 \cdot 5$ ) such as are found when the concentrate level of the ration is high and that otherwise the Ophryoscolecid population increases more rapidly than the holotrichs.

\section{Effect of the absence of rumen ciliates}

There was no significant difference in weight gain, food intake or general performance between animals with and without ciliates and this even in calves $F$ and $G$ subject to the stress of a low energy diet and in calves $N$ and $O$ put suddenly out to grass. The observation made by Pounden \& Hibbs (1950) of a rougher coat and more pot-bellied appearance in cilate-free calves was confirmed.

\section{Development of flagellate protozoa}

In both young calves and lambs, including isolated animals, when the $\mathrm{pH}$ was greater than 6.5 and there were few ciliates, a population of flagellates, particularly Trichomonas ruminantium Braune with smaller numbers of Chilomastix frontalis Braune, developed and flagellates were frequently observed in calves as early as 6 days. This agrees with the observations of Bryant \& Small (1960) and Lengemann \& Allen (1959). When ciliates became established the flagellates were reduced in number. As observed by Becker \& Everett (1930) direct contact is unnecessary for flagellate transfer since in the isolated ciliate-free calves and lambs the numbers of flagellates became exceptionally high and remained high in the adult animal unless the $\mathrm{pH}$ within the rumen dropped. These organisms seemed as intolerant of low $\mathrm{pH}$ as the ciliates.

\section{(a) Lambs}

\section{The establishment of bacteria}

In lambs a Gram smear picture of an 'adult' type, that is one in which there was a conspicuous background of small Gram-negative cocci, coccobacilli and rods, could become established as early as $\mathbf{1 5}$ days when the rumen conditions were not acid. This contrasted strikingly with the smear picture from rumen contents with a low $\mathrm{pH}$ where large Gram-positive and negative-rods, probably lactobacilli, were predominant and the background of small negative bacteria was inconspicuous if present at all.

Though Pounden \& Hibbs (1950) believed that both Oscillospira and the so-called 'window pane' sarcina referred to as Lampropedia by Hungate (1960), could only be transferred by direct contact between ruminants in the same way as rumen ciliate protozoa, both these organisms developed in isolated ciliate-free lambs. The 'window pane' sarcina was never present in large numbers in any lambs, but Oscillospira in numbers over $10^{5} / \mathrm{ml}$. was frequent and this organism reached particularly high numbers in the isolated lambs (Eadie \& Hobson, 1962). Quin's ovals and selenomonads also developed in considerable numbers in faunated and ciliate-free lambs. (See Moir \& Masson (1952) for illustrations of these organisms.) 
The first of these types of bacteria to be seen were invariably small selenomonads. These were followed by Quin's ovals and large selenomonads while Oscillospira was always the last to become established.

Table 4. Age of lambs (in days) when small selenomonads and Oscillospira were first observed in rumen samples taken weekly

$\begin{array}{rcc}\text { Lamb no. } & \text { Small Selenomonads } & \text { Oscillospira } \\ 305 & 53 & 104 \\ 327 & 56 & 78 \\ 90 & 28 & 56 \\ 92 & 27 & 55 \\ 94 & 23 & 37 \\ 91 & \text { Between } 22 \text { and } 57 * & 78 \\ 93 & 35 & 84 \\ 95 & 36 & 50 \\ 96 & 49 & 126 \\ 88 & 49 & 70 \\ 89 & 50 & 99 \\ 411 & 35 & 56 \\ 418 & \text { None seen by } 88 & \text { None seen by } 88 \\ 221 & \text { Between } 49 \text { and } 63 * & 70 \\ 222 & 49 & 63 \\ 230 & 32 & 39 \\ 231 & 25 & 54 \\ 232 & 28 & 70 \\ 241 & 30 & \text { None seen by } 44 \\ 242 & 35 & \text { None seen by } 44 \\ 245 & \text { None seen by } 44 \\ 246 & \text { None seen by } 44 & \text { None seen by } 44 \\ 247 & \text { None seen by } 44 & \\ \text { The intervening samples were abomasal contents. }\end{array}$

Table 4 illustrates the consistent order of arrival of organisms as well as certain variations between animals. Lambs 418, 241, 242, 245, 246 and 247 are of interest. In the first 3 weeks a mixed ciliate population had developed in several of these lambs but later they consumed considerable quantities of the ewe's concentrates. At the stage when small selenomonads were seen in lambs 241 and 245 these were the only two of this group in which a few ciliates, entodinia, remained. By 44 days all these lambs appeared to be ciliate-free, the rumen $\mathrm{pH}$ had dropped below 6.0 and small selenomonads were no longer visible. Thus the difference between the twins 241 and 242,245 and 246 could be accounted for by difference in rumen $\mathrm{pH}$ caused by a variation in concentrate consumption. However, the striking lag between the arrival of Oscillospira in the isolated ciliate-free lambs 95 and 96 cannot be so easily explained. At this stage both lambs were together in one pen and it would seem that lamb 96 had every opportunity for direct transfer of Oscillospira from lamb 95 in addition to the same opportunity for the more remote transfer effective in lamb 95. Moreover, there was no obvious difference in the rumen contents of 95 and 96 which might account for the 10 week lag, and 1 week after the organism was first observed in 96 , it had reached very high numbers.

Similarly the difference of one month in the times of arrival of Oscillospira in lambs 88 and 89 was unexpected. These lambs were fed together from 44 days and lamb 89 had had a mixed ciliate population from 43 days. Thus, if Oscillospira 
first develops under conditions suited to ciliate establishment, as seemed possible from earlier results, it would have been expected much earlier in lamb 89. It should be noted that the reduction in numbers of Oscillospira after the establishment of ciliates in isolated lamb 96 (Eadie \& Hobson, 1962) was a reduction to numbers comparable with those in a faunated animal on the same ration and did not indicate competition which would lead to the complete exclusion of Oscillospira.

Large numbers of a motile oval organism up to $12 \mu$ in length were occasionally observed in the isolated lambs (PI. 1, figs. 2, 3). Locomotory organelles were never visible. This organism has so far not been identified but it does not appear to correspond to any rumen organism so far described in the literature.

\section{(b) Calves}

Like the lambs, the lactobacillus Gram smear picture in calves with a rumen of low $\mathrm{pH}$ was very distinct from the 'adult' picture. The small organisms of the 'adult' picture appeared to be very similar to those in lambs or sheep. There was no difference between calf 86 and the calves of group $(a)$ Table 2 , so that as in Rusoff \& Davis' observations (1951), aureomycin did not have a striking effect on the flora.

There was one distinct contrast between the observations in calves and lambs; the large bacteria-Selenomonas species Quin's ovals and Oscillospira-were never conspicuous in calves, even though they were invariably present in the routine rumen inocula which were taken from sheep. Even an inoculum of whole rumen liquor from an isolated lamb, in which were very high numbers of Oscillospira, failed to establish this organism in calf $\boldsymbol{F}$. The only occasions when Oscillospira persisted, and then only in small numbers, were in calf $O$ and to a lesser extent in calf $N$ after these animals had been in contact with other calves in a field. In calf $O$ small numbers of Oscillospira were present for 4 months.

It is difficult to explain the lack of 'large bacteria' in the calves when in every other respect the lamb and calf bacterial pictures were very similar. The low numbers of Oscillospira in isolated calves are especially remarkable since Pounden \& Hibbs (1950) when working with an isolated ciliate-free calf which had been accidentally contaminated with normal calf rumen fluid, observed vast numbers of Oscillospira, an observation entirely comparable with those recorded for the isolated lambs discussed above. Although calf $\boldsymbol{Z}$ was kept for 8 weeks in a crate about $9 \mathrm{ft}$. away from some adult roughage-fed cattle and the dairy herd, and might be expected to have been subject to aerial contamination with Oscillospira, none of these organisms developed in the calf. Even when calf $Z$ was directly inoculated with $100 \mathrm{ml}$ of whole rumen contents from isolated lambs on a similar ration but containing many Oscillospira, the organisms failed to develop. A very few organisms, circa 20/ml., were observed during the first $\mathbf{3}$ days following the inoculation but they completely disappeared after this.

It would seem, therefore, that some feature of the calf rumen fluid was unsuited to the development of Oscillospira. As with other calves neither Quin's ovals nor selenomonads developed in calf $\boldsymbol{Z}$. The ' window pane' organisms were more frequent and more numerous in calves than in lambs. 


\section{Inter-relationships between bacteria and ciliate protozoa}

Except in the early-weaned calves 3 and 4 (Eadie et al. 1959), the only observations of the 'small bacteria' in the present work were from direct films so that generalizations on the flora can be made only with care. However, the observations on the relationship between the number of lactobacilli which was controlled by diet, and ciliate establishment were quite general. Also, where ciliates were present in abundance the normal 'adult' type Gram-negative background to the film was invariably present and this even in the case of very young calves where a mixed ciliate population was present only for a few days. A number of workers, including Pounden \& Hibbs (1948a), and Huhtanen, Saunders \& Gall (1951), have noted differences in flora between normal young calves and mature animals. From the present work it appears that it is ration rather than age which determines the predominant bacteria in exactly the same way as it controls the ciliate development, and the 'adult' bacterial picture is normally associated with ciliates and a high rumen $\mathbf{p H}$.

The presence of a significantly greater number of bacteria in the isolated ciliatefree lambs compared with the control lambs with ciliates, has been discussed (Eadie \& Hobson, 1962). On inoculation with ciliates the total number of bacteria in isolated lamb 96 dropped considerably and the same was clearly true for lamb 222 although counts were not made. However, the morphological types of bacteria in isolated ciliate-free lambs and calves made up an 'adult type' population which did not differ markedly from that in the inoculated controls, except for a distinctive, large, parallel-sided, granular-staining, Gram-positive rod (Pl. 1, fig. 1) which was present in considerable numbers for a period of time in all ciliate-free animals on a high roughage diet. This organism did not remain permanently in isolated animals but it was observed as early as 5 weeks in several lambs and it stayed for 5 months in one case where isolation was prolonged. It was never observed in animals with rumen ciliates, nor was it seen under ciliate-free, acid ruminal conditions. In calves 610 and 611 which had been kept free from ciliates initially because of the highconcentrate weaning ration and consequent low rumen $\mathrm{pH}$, this characteristic rod developed during a short period of roughage feeding. As the isolated animals were kept at different times and in different houses, it seems that the conditions cited above, namely the ciliate-free rumen of a roughage-fed young animal, are particularly favourable for this organism. Pounden (personal communication) has noted a Gram-positive granular rod associated with isolated calves but it is impossible to compare the organisms without cultural observations.

\section{The components of the ciliate population}

As mentioned earlier, a mixture of Entodinium species, holotrichs and large Ophryoscolecid organisms could develop in the very young animal and a mixed population is typical of the normal domestic or wild ruminant except that the holotrichs are sometimes absent. The only Ophryoscolecid which always failed to become established when inoculated into the young animals, was Ophryoscolex tricoronatus. It was frequently present in the inocula for lambs $51,52,305,327$ and calves $X$ and $P$. When conditions in the rumen had been acid entodinia always appeared first in lambs. However, in general where a lamb was with the ewe a mixed population 
developed which represented in the number of species and their relative proportions that found in the parent animal. Thus, the population was that which might be expected to develop after direct contact. However, the relationship between the ciliates which developed in the inoculated lambs and calves and those present in the artificial inocula, was more complex and will be discussed in detail by Eadie (1962).

\section{GENERAL CONCLUSIONS}

It has been established that both lambs and calves can develop a mixed ciliate population at a very early stage given a high $\mathrm{pH}$ in the rumen, and that the degree of acidity takes precedence over the source of inoculum or the age of the animal in governing the development of both a mixed ciliate fauna and an 'adult' type flora.

The general pictures for the establishment of ciliates in lambs and calves were very similar and comparable, as were the bacterial pictures, except that very few Quin's ovals, selenomonads and Oscillospira ever developed in calves. Direct contact between animals has been proved to be unnecessary for the transfer of these bacteria. A characteristic large Gram-positive granular rod was noted to be present for some time in all roughage fed, ciliate-free animals. In neither calves nor lambs (see Eadie \& Hobson, 1962) was there any significant difference in general performance between animals maintained with and without ciliates. It seems possible that small ciliates can be dispersed further from cattle than from sheep and that this has to be taken into account when isolating the animals in order to keep them ciliate-free.

Despite these generalizations made from observations on 58 animals there still remained certain individual variations between animals which could not be accounted for by difference in management and this type of variation has been noted by previous workers (Bryant \& Burkey, 1953; Bryant \& Small, 1960). This stresses the importance of basing conclusions on a sufficiently large number of animals with additional controls kept at different times. The general picture for a given treatment has proved to be similar but the actual arrival times and comparative numbers of various organisms varied considerably and presumably indicated certain internal conditions of the host which had to be attained before establishment was possible. Probably the acid rumen associated with a high concentrate ration is the only condition in which the organisms can be relied upon to develop as predicted.

I should like to express my thanks to Dr P. N. Hobson for much helpful discussion and to Mr S. O. Mann for his ready advice on the bacterial section of this work. I am also grateful to Dr T. R. Preston for access to a considerable number of his early-weaned calves. I am indebted to Mr B. F. Fell for the photograph (PI. 1, fig. 1), and to Mr Jabez Bruce for the U.V. photographs. Finally, my most sincere thanks to Mr W. Shand for invaluable technical assistance throughout this work. 


\section{REFERENCES}

Becker, E. R. \& Everett, R. C. (1930). Comparative growth of normal infusoria-free lambs. Amer. J. Hyg. 11, 362.

Becker, E. R. \& Hsiung, T. S. (1929). The method by which ruminants acquire their fauna of infusoria and remarks concerning experiments on the host specificity of these protozoa. Proc. Nat. Acad. Sci., Wash. 15, 684.

Briggs, P. K., Hogan, J. P. \& REID, R. L. (1957). The effect of volatile fatty acids, lactic acid and ammonia on rumen $\mathrm{pH}$ in sheep. Aust. J. agric. Res. 8, 674 .

Bryant, M. P. \& Burkey, L. A. (1953). Numbers and some predominant groups of bacteria in the rumen of cows fed different rations. J. Dairy Sci. 36, 218.

Bryant, M. P. \& SMall, N. (1960). Observations on the ruminal micro-organisms of isolated and inoculated calves. J. Dairy Sci. 43, 654 .

Bryant, M. P., Small, N., Bouma, C. \& Robinson, I. (1958). Studies on the composition of the ruminal flora and fauna of young calves. J. Dairy Sci. 41, 1747.

Eadre, J. M. (1959). Some aspects of rumen ciliate protozoa. Proc. Nutr. Soc. 18, 123.

EADIE, J. M. (1962). Inter-relationships between certain species of rumen ciliate protozoa. J. gen. Microbiol. 29, 579.

Eadie, J. M. \& Hobson, P. N. (1962). Effect of the presence or absence of rumen ciliate protozoa on the total bacterial count in lambs. Nature, Lond. 193, 503.

Eadie, J. M., Hobson, P. N. \& ManN, S. O. (1959). A relationship between some bacteria, protozoa and diet in early-weaned calves. Nature, Lond. 183, 624.

EAdie, J. M. \& OXFond, A. E. (1955). Factors involved in the production of a novel kind of derangement of storage mechanism in living holotrich ciliate protozoa from sheep rumen. J. gen. Microbiol. 12, 298.

Eadie, J. M. \& Oxford, A. E. (1957). A simple and safe procedure for the removal of holotrich cilates from the rumen of an adult fistulated sheep. Nature, Lond. 179, 485.

Hungate, R. E. (1960). Microbial ecology of the rumen. Bact. Rev. 24, 365.

Huhtanen, C. N., Saunders, R. K. \& Gall, L. S. (1951). Some differences in adult and infant rumen flora of cattle on practical rations. J. anim. Sci. 10, 1049.

Lengemann, F. W. \& Allen, N. N. (1959). Development of rumen function in the dairy calf. II. Effect of diet upon characteristics of the rumen flora and fauna of young calves. J. Dairy Sci. 42, 1171.

MoIr, R. J. \& Masson, M. J. (1952). An illustrated scheme for the microscopic identification of the rumen micro-organisms of sheep. J. Path. Bact. 64, 343.

Phillipson, A. T. (1955). In Advances in Veterinary Science, vol. II, p. 238. New York: Academic Press, Inc.

Pounden, W. D. \& HibBs, J. W. (1948a). The influence of the ration and rumen inoculation on the establishment of certain micro-organisms in the rumen of young calves. J. Dairy Sci. 31, 1041.

Pounden, W. D. \& Hibss, J. W. (1948b). The influence of the ratio of grain to hay in the ration of dairy calves on certain rumen micro-organisms. J. Dairy Sci. 31, 1051.

Pounden, W. D. \& HibBs, J. W. (1949). The influence of pasture and rumen inoculation on the establishment of certain micro-organisms in the rumen of young dairy calves. J. Dairy Sci. 32, 1025.

Pounden, W. D. \& Hibbs, J. W. (1950). The development of calves raised without protozoa and certain other characteristic rumen micro-organisms. J. Dairy Sci. 33, 639.

Preston, T. R. (1958). The value of rumen inoculations and of diets containing sweetening agents for calves weaned on to dry food at three weeks of age. Proc. Brit. Soc. Anim. Prod. p. 33.

Purser, D. B. \& MoIr, R. J. (1959). Ruminal flora studies in sheep. IX. The effect of pH on the ciliate population of the rumen in vivo. Aust. J. agric. Res. 10, 555.

Rusoff, L. L. \& DAvis, A. V. (1951). Growth-promoting effect of aureomycin on young calves weaned from milk at an early age. $J . N u t r .45,289$. 
Smiles, J. \& Dobson, M. J. (1956). Direct ultra-violet and ultra-violet negative phase contrast micrography of bacteria from the stomachs of the sheep. J. R. micr. Soc. 75, 244.

Walker, D. M. (1959). The development of the digestive system of the young animal. III. Carbohydrase enzyme development in the young lamb. J. agric. Sci. 53, 374.

\section{EXPLANATION OF PLATE 1}

Fig. 1. Large granular-staining Gram-positive rod from an isolated calf. 'A' indicates two particularly typical organisms $(\times 2,300)$.

Fig. 2. Large oval organism from isolated lamb with normal bacterial background and one Oscillospira organism. Direct U.V. illumination, $\lambda 2536$ A. $(\times 2240)$.

Fig. 3. Large oval organism partially separated from debris and showing some visible internal structure. One dividing organism is shown. Direct U.V. illumination $(\times \mathbf{2 2 4 0})$. 


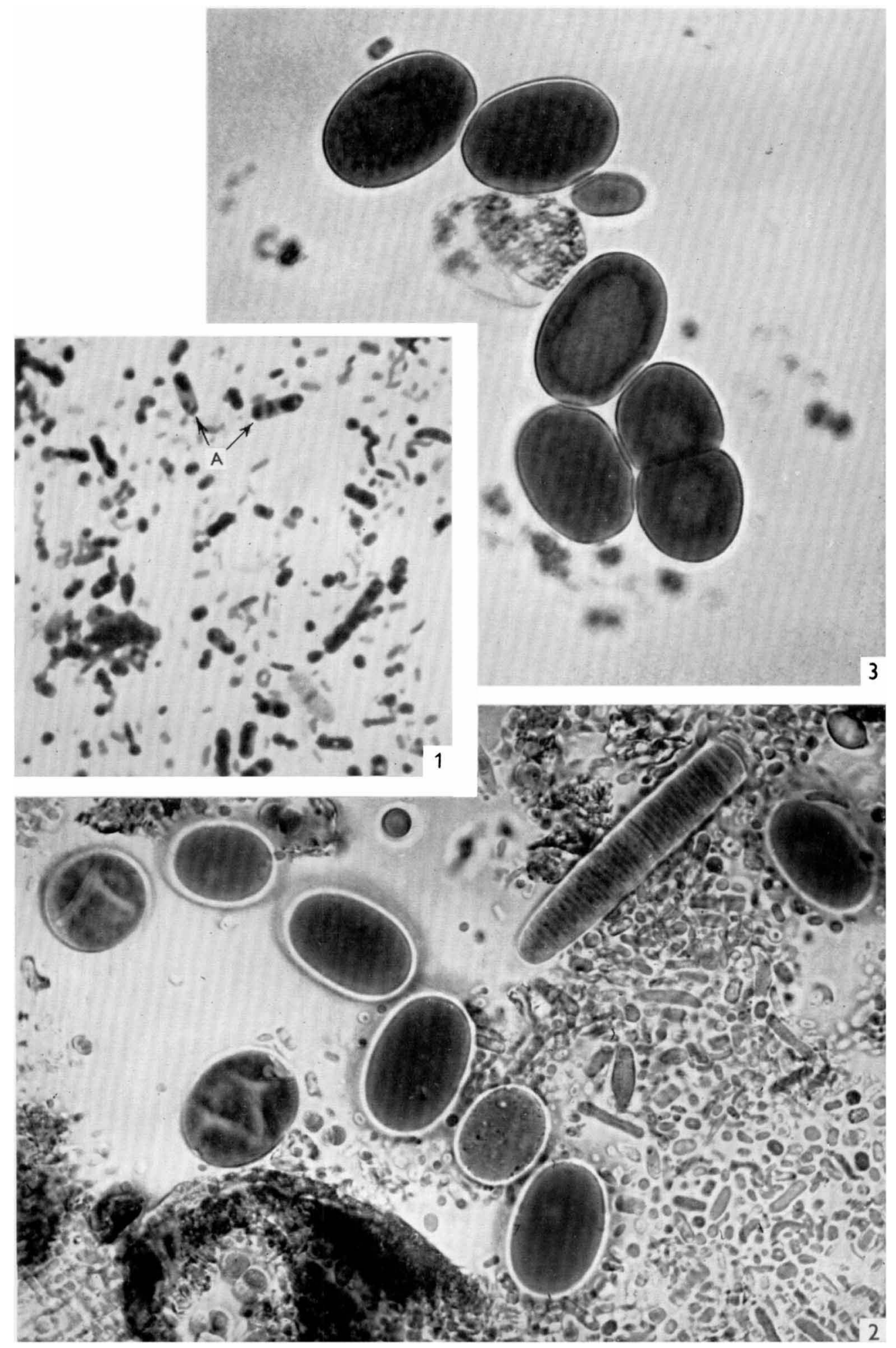

